\title{
A cluster of aspartic residues in the extracellular loop II of PAR 4 is important for thrombin interaction and activation of platelets
}

Daniel Sanchez Centellas, Sushanth Gudlur, Alejandro Vicente Carrillo, Sofia

Ramström and Tomas Lindahl

The self-archived version of this journal article is available at Linköping University Electronic Press:

http:/ / urn.kb.se/ resolve?urn=urn:nbn:se:liu:diva- 138473

N.B.: When citing this work, cite the original publication.

Sanchez Centellas, D., Gudlur, S., Vicente Carrillo, A., Ramström, S., Lindahl, T., (2017), A cluster of aspartic residues in the extracellular loop II of PAR 4 is important for thrombin interaction and activation of platelets, Thrombosis Research, 154, 98-106.

https:// dx.doi.org/ 10.1016/j.thromres.2017.04.006

Original publication available at:

https:// dx.doi.org/ 10.1016/j.thromres.2017.04.006

Copyright: Elsevier

http:// www.elsevier.com/

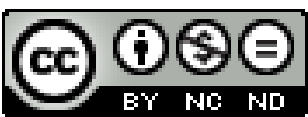




\section{A cluster of aspartic residues in the extracellular loop II of PAR 4 is important for thrombin interaction and activation of platelets}

Daniel Sánchez Centellas ${ }^{1}$, Sushanth Gudlur ${ }^{1 \neq}$, Alejandro Vicente-Carrillo ${ }^{1}$, Sofia Ramström $^{1}$ and Tomas L. Lindahl ${ }^{1,2^{*}}$

${ }^{1}$ Department of Clinical and Experimental Medicine, Linköping University, and ${ }^{2}$ Department of Clinical Chemistry and Department of Clinical and Experimental Medicine, Linköping University, Linköping, Sweden.

${ }^{\#}$ Current Address: Center for Biomimetic and Sensor Science, School of Materials Science and Engineering, Nanyang Technological University, Singapore

*Corresponding author

\section{ABSTRACT}

Thrombin activates platelets via proteolytic cleavage of protease-activated receptors (PARs) 1 and 4. The two PARs have distinct but complementary roles. The mechanisms responsible for PAR1 activation by thrombin have been extensively studied. However, much less is known regarding thrombin activation of PAR4, especially the potential involvement of regions of PAR4 other than the N-terminal, which is bound to the catalytic site of thrombin.

We have studied PAR4 in S. Cerevisiae strain MMY12, an expression system in which the GPCR receptors are connected to a Lac Z reporter gene resulting in increased $\beta$ galactosidase activity. This approach was used to assess PAR4 mutants to evaluate the contribution of different aspartic residues in facilitating PAR4 activation. Furthermore, peptides mimicking parts of the PAR4 N-terminal and the second extracellular loop 
(ECLII) were tested for their ability to inhibit platelet activation by thrombin. Binding of these peptides to $\gamma$-thrombin was studied by monitoring the decrease in tryptophan fluorescence intensity of thrombin.

We conclude that not only the N-terminal but also the electronegative aspartic residues D224, D230 and D235 (located in ECLII) are be important for PAR4 binding to thrombin. We further suggest that they play a role for the tethered ligand binding to the receptor, as mutations also affected activation in response to a PAR4-activating peptide mimicking the new $\mathrm{N}$-terminal formed after cleavage. This agrees with previous results on PAR1 and thrombin binding. We suggest that the ECLII of PAR4 could be a potential target for antithrombotic drug development.

\section{Introduction}

Thrombin is one of the most potent platelet agonists, acting via two protease-activated receptors (PARs), PAR1 and PAR4. The N-terminal exodomain of these receptors are cleaved off, and the unmasked newly exposed $\mathrm{N}$-terminus serves as a tethered ligand docking intra-molecularly onto the receptor, thereby inducing signaling through its coupled $G$ proteins $[1,2]$. Although the evolutionary benefits of this seemingly redundant dual receptor configuration are unknown, emerging clinical and experimental evidence support the notion that the two PAR receptors have distinct but complementary roles in platelet biology. While platelets respond with a transient "spike” in the intracellular calcium concentration upon stimulation of PAR1, PAR4 stimulation gives rise to a much more prolonged calcium mobilization, supposedly due to different kinetics of receptor phosphorylation and internalization [2]. PAR1 is more sensitive to low concentrations of thrombin than PAR4 [1] and is more effective in rapidly mobilizing platelet haemostatic functions, such as the release of bioactive cargo 
stored in granules [3]. Maximal activation of PAR4 results in more fibrinogen bound to the platelet and a higher clot elasticity [4]. PAR1 has also been shown to be more susceptible to desensitization than PAR4 [5].

The catalytic activity and specificity of thrombin is highly dependent on two intramolecular recognition sites located distant from the active site. These domains, designated fibrinogen recognition site and heparin binding site, or exosite I and II respectively, facilitate proteolysis by interacting with anionic surfaces on various substrates, and are the target of several physiologically important thrombomodulatory agents including antithrombin [6]. Exosite I is the binding epitope for fibrinogen, thrombomodulin, hirudin, and PAR1. Exosite II binds to heparin and potentially also to GPIb [7-10]. Exosites I and II on thrombin may be blocked by the DNA-oligomers HD1 and HD22, respectively [11]. The binding of thrombin exosite I to PAR1 is mediated by a hirudin-like sequence immediately downstream of the tethered ligand domain. This sequence does not exist on PAR4. Instead, thrombin has been reported to have low affinity for the thrombin cleavage site of PAR4 [12]. Both PAR1 and PAR4 can cause platelet activation and aggregation single-handedly, but the activation of PAR4 by thrombin is accelerated by the presence of PAR1 [13], suggesting a cofactor function for PAR1.

PAR1 is a typical G protein coupled receptor (GPCR), comprised of seven transmembrane helices that are connected by intracellular and extracellular loops, and are arranged around a central pocket [14]. Extracellular loop II (ECLII) is located between transmembrane helices 4 and 5. In PAR 1, ECLII is a binding site for the tethered ligand [15] but very little is known about the homologous region on PAR4. Both PAR1 and PAR4 display a high concentration of anionic residues in ECL II, and the same is true for the N-terminal region of both receptors. Work by Nieman's group 
has shown that anionic residues in the $\mathrm{N}$-terminal of PAR4 are important for its interaction with $\alpha$-thrombin both in the presence and absence of PAR1 [16]. In a previous report, we presented evidence for a pivotal role for exosite II in PAR4dependent activation of platelets by thrombin [17]. There are also reports stating that the exosite II residue W215 in thrombin is important as it affects thrombin activation of platelets via hydrophobic interactions [18].

The location and features of thrombin's exosite II makes it difficult to study as it is composed by several amino acids arising from different chains, but it is known that the residues R93, R101, R233, K235, K236, and K240 are important for thrombin’s interaction with heparin [10] and with GpIb. So, we can assume that amino acids of PAR4 that interact with exosite II would most likely be anionic ones, to facilitate electrostatic interactions. For this reason, in this work, we chose to study how specific electronegative amino acids within the N-terminal and ECLII of PAR4 contribute to PAR4 activation. To help investigate the mechanism, $\gamma$-thrombin, a non-physiological proteolytic product of $\alpha$-thrombin which lacks exosite I was used as a tool. In addition, we designed short peptides that mimic the N-terminal and extracellular domains of PAR4 as candidates for the interaction with exosite II on thrombin. Our results indicate a role for ECLII in thrombin activation of PAR4 and as the binding partner for the newly formed N-terminal of PAR4 after cleavage by thrombin. 


\section{Materials and Methods}

Chemicals All peptides were purchased as lyophilized powders. Except for PAR4activating peptide (PAR4-AP, sequence AYPGKF) which was purchased from JPT Peptide Technologies GmbH (Berlin, Germany), all other peptides were purchased from GeneCust (Dudelange, Luxembourg) with a certified purity of $99.5 \%$. Stock peptide solutions were prepared at $10 \mathrm{mM}$ concentrations in deionized water. Peptide properties are listed in Table 2. $\alpha$-thrombin was purchased from Sigma Aldrich (St Louis, MO, US) and dissolved to a stock solution of $200 \mathrm{U} / \mathrm{mL}$, which is equivalent to $1360 \mathrm{nM} . \gamma$ thrombin (a thrombin variant lacking exosite I) was purchased from Coatech (Gothenburg, Sweden) and dissolved to make a stock concentration of $1 \mu \mathrm{M} . \gamma$ thrombin for binding assays were purchased as lyophilized powder with a certified purity higher than 99\% from Enzyme Diagnostic Research (Swansea, UK). Apyrase from potato, grade VI, Ref A6535 was purchased from Sigma Aldrich. HEPES buffer (145 mM NaCl, 5 mM KCl, 1 mM MgSO 4,10 mM HEPES and 10 mM glucose, pH 7.4) and Krebs Ringer Glucose (KRG) solution were prepared. SCH79797 was purchased from Tocris (Bristol, UK), DNA-aptamers HD1 and HD22 were from Biomers.net (Ulm, Germany). A cocktail of protease inhibitors was purchased from Thermo Fisher (Waltham, MA, US).

\section{Cloning, directed mutagenesis, transformation, and expression of PAR4 in Saccharomyces cerevisiae}

PAR4 cDNA was kindly provided by Dr Kuliopulos (Tufts University, Boston, MA US) and inserted into the plasmid pcDEF3 by the restriction sites EcoRI at mi' 5' end and XbaI at 3' end, using E. coli strain DH10B for subcloning and plasmid propagation platform. The destination plasmid (Supplemental Table 1) for yeast expression of 
pG426 was kindly provided by Dr Simon Dowell (GSK, Stevenage, UK). The cloning strategy was performed by inserting PAR4 restricted fragment of pCDEF3 upstream and downstream of the PAR4 cDNA in an open reading frame and saving their Kozak sequences of the cDNA using the restriction sites 5minSpeI and 3minSmaI. Ligation (see plasmids used in Supplemental Table 2) was confirmed by restriction and sequencing. BMH 71-18 mutS E. coli strain from was used to perform directed mutagenesis provided its defective mutation to repair DNA mismatches while DH10B E. coli strain was used for ligation experiments and plasmid propagation. The resulting p426GPD-PAR4 plasmid was used as a platform for PAR4 directed mutagenesis using the Transformer kit from Clontech (Mountain View, CA, US) following the manufacturer's instructions, see Supplementary Table 2 for strain used. Primers used for this purpose are listed in Supplemental Table 2. Both mutated and native PAR4 cDNAs were transformed in yeast strain MMY12 (also kindly donated by Dr Simon Dowell). The method to transform yeast was a modification of the Geitz method [19], as described by Dowell and Brown [20]. Positive clones for transformation were selected by auxotrophic growth on minimal -Uracil media.

\section{Lac $Z$ reporter assay and $\beta$-galactosidase measurement}

An overnight culture of yeast cells grown in selective media WHAUL+His-Ura was diluted 5 times using the same media to reach a logarithmic phase of growth until an $\mathrm{OD}_{600 \mathrm{~nm}}$, of $0.8-1$, and then treated for 15 min with 20 units of zymolyase (from a stock at $5 \mathrm{U} / \mu \mathrm{L}$ in PBS) (AMSBIO, Abingdon, $\mathrm{UK}$ ) to remove the cell wall and produce yeast spheroplasts. After treatment with $\alpha$ - , $\gamma$-thrombin, PAR4-activting peptide or vehicle, incubation at RT for 20 min and then stopped by freezing, the yeast spheroplasts were centrifuged at 10,000x g for 1 min and re-suspended in the same volume of $\mathrm{Z}$ buffer $\left(\mathrm{Na}_{2} \mathrm{HPO}_{4} \bullet 7 \mathrm{H}_{2} \mathrm{O} 16.1 \mathrm{~g} / \mathrm{L}, \mathrm{NaH}_{2} \mathrm{PO}_{4} \bullet \mathrm{H}_{2} \mathrm{O} 5.50 \mathrm{~g} / \mathrm{L}, \mathrm{KCl} 0.75 \mathrm{~g} / \mathrm{L}, \mathrm{MgSO}_{4} \bullet 7 \mathrm{H}_{2} \mathrm{O}\right.$ 
$0.246 \mathrm{~g} / \mathrm{L}, \mathrm{pH} 7)$. The spheroplasts were washed again by centrifuging at the same speed and the pellet thoroughly re-suspended in a final volume of $250 \mu \mathrm{L}$ of $\mathrm{Z}$ buffer containing $0.2 \%$ of $\beta$-mercaptoethanol and $4 \mathrm{mg} / \mathrm{mL}$ O-nitrophenyl- $\beta$-Dgalactopyranoside (ONPG), (Sigma Aldrich, St. Louis, MO, US). Time was recorded until enough yellow color appeared in the solution, the reaction was then quenched with $1 \mathrm{M}$ of $\mathrm{Na}_{2} \mathrm{CO}_{3}$.The solution was cleared by centrifugation at $1,000 \mathrm{x} \mathrm{g}$ for $1 \mathrm{~min}$ and absorbance at $410 \mathrm{~nm}$ was recorded for the supernatant using Fluoroskan Ascent FL (Thermo Electron Corporation, Waltham, US). The $\beta$-galactosidase units were calculated using the formula: Abs $410 \mathrm{~nm}$ x 1,000/ ((OD $600 \mathrm{~nm}$ culture) x (incubation time) $\mathrm{x} 2)$ ) dilution factor is due to the use of $0.25 \mathrm{~mL}$ of sample lysate on $0.5 \mathrm{~mL}$ of reagent. The formula and method was based on the method described by Dowell and Brown [20].

\section{Blood collection and platelet preparation}

Blood was collected from healthy donors after informed consent and approval from the local ethics committee. From heparinized containers $(10 \mathrm{IU} / \mathrm{mL})$ the blood was transferred to $50 \mathrm{~mL}$ Falcon tubes and mixed with anticoagulant citrate dextrose (ACD) solution 5:1 (v:v) (71 mM citric acid, $85 \mathrm{mM}$ sodium citrate and $111 \mathrm{mM}$ glucose) and centrifuged at $220 \mathrm{x}$ g for 20 min to obtain platelet-rich plasma which was then incubated with $0.5 \mathrm{U} / \mathrm{mL}$ apyrase, followed by centrifugation at $520 \mathrm{x}$ g for $20 \mathrm{~min}$ to collect the platelets. The platelet solution was carefully washed three times by exchanging supernatant with Krebs-Ringer glucose (KRG) buffer (120 mM NaCl, 4.9 mM KCl, $1.2 \mathrm{mM} \mathrm{MgSO}_{4}, 1.7 \mathrm{mM} \mathrm{KH}_{2} \mathrm{PO}_{4}, 8.3 \mathrm{mM} \mathrm{Na}_{2} \mathrm{HPO}_{4}$ and $10 \mathrm{mM}$ glucose, $\mathrm{pH}$ 7.3) and finally re-suspended in KRG containing $1 \mathrm{U} / \mathrm{mL}$ apyrase. The platelet count was measured using a blood cell counter (ABX Diagnostics Micros 60, Ramsey, MN, USA or Swelab Alfa Basic Cell Counter, Swelab, Spånga, Sweden) and adjusted to 
$2.5 \times 10^{8}$ platelets/mL. Suspensions were supplemented with $1 \mathrm{mM} \mathrm{CaCl}_{2}$ before use. For cleavage assays, $\alpha$ or $\gamma$-thrombin were added at the final working concentration (see each setting in results) in the platelet suspension, with or without other additions, as stated in figure legends. After incubation at RT for 20, the samples were immediately frozen using dry ice. After brief thawing at $37^{\circ} \mathrm{C}$ of samples, they were treated for Western Blot as described below.

\section{Flow cytometry}

Flow cytometry was performed on a Coulter Epics XL.MCL flow cytometer with Expo 32 ADC software from Beckman Coulter (Brea, CA, US). Fluorosphere control samples (Flow-Check ${ }^{\mathrm{TM}}$ and Flow-Set ${ }^{\mathrm{TM}}$ ) from the same supplier were analyzed every day. Washed platelets were incubated with a FITC-conjugated antibody detecting the fibrinogen receptor GPIIb/IIIa in its active state (PAC-1-FITC, $2 \mu \mathrm{g} / \mathrm{mL}$, from BD Biosciences, San Jose, CA, USA) or a chicken anti-human FITC-conjugated anti-Pselectin $(0.24 \mu \mathrm{g} / \mathrm{mL}$, from Diapensia HB, Linköping, Sweden), peptides mimicking the N-terminal or ECLII of PAR4 at 300 and $600 \mu \mathrm{M}, \mathrm{HD} 1$ or HD22 at $2 \mu \mathrm{M}, \alpha-$ thrombin at $14 \mathrm{nM}$ or $\gamma$-thrombin at $20 \mathrm{nM}$ and HEPES buffer to give a final volume of $65 \mu \mathrm{L}$. The reaction was stopped after $16 \mathrm{~min}$ by the addition of $1 \mathrm{~mL}$ cold HEPES buffer. The platelet population was identified by its light scattering properties. A cut-off was set in the FITC fluorescence channel to divide a platelet population containing nonbinding antibody (a FITC-conjugated rabbit anti-IgY, from Diapensia) with corresponding fluorescence intensity into two fractions, one that contained 98.5-99.5\% of the platelets and the other containing the brightest $0.5-1.5 \%$ of the platelets. Platelets with fluorescence intensity higher than this cut-off were identified as fibrinogen binding or P-selectin positive cells, respectively. Control samples without thrombin were run for 
each donor to ensure that the platelets were not pre-activated. All samples were tested in duplicates.

\section{SDS-PAGE gel electrophoresis and Western Blotting}

Western blotting of platelet proteins was performed essentially as described before [17]. Samples were incubated in KRG buffer with/without agonist and thereafter mixed with 80-100 $\mu \mathrm{L}$ of lysis buffer (Tris-HCl $50 \mathrm{mM} \mathrm{pH} 7.5+2 \%$ Tween + protease inhibitor cocktail (Thermo Fisher, Waltham, MA, USA). After a brief vortex, samples were frozen at $-70^{\circ} \mathrm{C}$ for $15 \mathrm{~min}$ and exposed to three thawing cycles in total. This was followed by a short centrifugation to pellet debris after which the supernatant was collected and the protein concentration measured using the micro-BCA method (Thermo Fisher, Waltham, MA, USA). For yeast, the protein extract was obtained from $1 \mathrm{~mL}$ of pelleted logarithmic culture resuspended in $100 \mu \mathrm{L}$ of buffer (50 mM Tris-HCl (pH 8.0), 100 mM NaCl, 1 mM EDTA, 5 mM MgCl 2,1 mM DTT, supplemented with fresh protease inhibitor cocktail 1/100 (Thermo Fisher, Waltham, MA, USA)). After two freeze-thawing cycles $\left(10 \mathrm{~min}\right.$ at $-70^{\circ} \mathrm{C}$, then $5 \mathrm{~min}$ at $42^{\circ} \mathrm{C}$ in a water bath), the solution was vigorously vortexed with acid washed glass beads for 1 min (SigmaAldrich, St Louis MO, US) after which the lysate was chilled on ice for $10 \mathrm{~min}$, centrifuged at maximum speed for $1 \mathrm{~min}$ and the supernatant collected. In all cases, proteins were treated with denaturing Laemmli buffer $5 \mathrm{x}$ and heated as usual for this procedure, electrophoresis of proteins was then performed in NuPAGE precast gels (Thermo Fisher) at constant voltage of $125 \mathrm{~V}$ for gel in MOPS buffer, provided in the precast gel kit. Electro-transference to PVDF membrane (pre-activated with methanol) was done at a constant intensity of $125 \mathrm{~mA} /$ membrane, followed by membrane blocking with TBS-T (20 mM Tris, $137 \mathrm{mM} \mathrm{NaCl}+0.1 \%$ Tween 20, pH 7.5) including 5\% dry skim milk during $1 \mathrm{~h}$ under gentle shaking, and incubation with primary antibody 
against human PAR4 (mouse monoclonal clone 5F4, dissolved in TBS-T $+5 \%$ bovine serum albumin (BSA) from Abnova (Taipei, Taiwan)) usually overnight at $4^{\circ} \mathrm{C}$ under gentle shaking. Alternatively, we used a mouse monoclonal anti GAPDH antibody, clone GA1R, at 1:5000 dilution from ThermoFisher Scientific (Rockford, IL, US) for the experiments to check the loading control. Next day, membranes were washed in TBS-T, followed by secondary antibody incubation at a dilution between 1/2000-1/3000 (HRP-conjugated Goat anti-mouse Fc from Cell Signaling Technology (Boston, MA, US) for 1 hour at RT and finally washed again as described in Boknas et al (17). Binding was detected by reaction with a commercial ECL reagent $\left(\operatorname{Immobilon}^{\mathrm{TM}}\right.$, Millipore, Merck, Darmstadt, Germany), photographic film exposure was performed in a photographic dark chamber FUJI LAS-1000 under the control of Image Reader software V2.6 (Minato, Tokyo Japan).

\section{Light transmission aggregometry}

Aliquots $(0.5 \mathrm{~mL})$ of platelet suspension (approximately at 2,500 platelets/ $\mu \mathrm{L})$ were preincubated at $37^{\circ} \mathrm{C}$ for $2 \mathrm{~min}$. The blank was set with dilution buffer for platelets (KRGbuffer) at the same time for all channels. Platelet suspensions were added and initially run for 3-4 min to check for spontaneous aggregation, if this occurred, the preparation was discarded. Thereafter, platelet aggregation was induced by adding thrombin or ADP in the presence or absence of the PAR4-mimicking peptides. Changes in light absorbance were recorded using a Chronolog Dual Channel lumi-aggregometer (Model 560, Chrono-Log, Haverston, PA, US).

\section{Enzymatic activity of thrombin}

The enzymatic activity of thrombin was recorded by use of a fluorogenic substrate ZGly-Gly-Arg-AMC, final concentration $0.4 \mathrm{mM}$. $\alpha$-thrombin at $14 \mathrm{nM}$ or $\gamma$-thrombin at 
$20 \mathrm{nM}$ was incubated in presence or absence of the PAR4 peptides, final concentration $600 \mu \mathrm{M}$ and the fluorescence measurements were recorded for $20 \mathrm{~min}$.

\section{Tryptophan fluorescence studies of PAR4 peptides binding to $\gamma$-thrombin.}

Binding of PAR4 peptides to $\gamma$-thrombin was studied by monitoring the decrease in tryptophan fluorescence intensity of thrombin at its $\lambda_{\max }(341 \mathrm{~nm})$ as a function of PAR4 peptide concentration. Fluorescence intensity measurements were performed on 1 $\mu \mathrm{M}$ thrombin in PBS by exciting at $295 \mathrm{~nm}$ and collecting emission spectra between $310-500 \mathrm{~nm}$ using a slit width of $5 \mathrm{~nm}$. All fluorescence measurements were performed at $22^{\circ} \mathrm{C}$ using a Horiba JobinYvon (Kyoto, Japan) Fluoromax-4 spectrofluorimeter fitted with a Peltier model temperature control system.

Stock solutions of PAR4 peptides (12-20 mM) were prepared by dissolving peptides initially in DMSO and subsequently diluting with PBS to a final DMSO concentration of $5 \%$. Small aliquots $(0.5-5 \mu \mathrm{L})$ of these stock peptide solutions were titrated into a cuvette containing $400 \mu \mathrm{L}$ of $1 \mu \mathrm{M}$ thrombin in PBS. Total peptide solution added did not exceed $7 \%$ of final volume. The samples were mixed thoroughly after each peptide addition and before fluorescence measurement. Control experiments to check for nonspecific peptide binding to thrombin was performed, in which thrombin was titrated with a PAR4 peptide control peptide pseudo 223-239 whose amino acid sequence was scrambled. All spectra were corrected to remove background signal from buffer. Peptide concentrations were determined using Micro-BCA assay (Thermo Fischer), and the concentration of thrombin was determined using its absorbance at $280 \mathrm{~nm}$ and an extinction co-efficient (1\%) of 18.3. 
The change in fluorescence intensity of thrombin upon peptide addition obtained from the above experiments was first expressed as

$\left(\mathrm{F}_{\mathrm{obs}}-\mathrm{F}^{0}\right) / \Delta \mathrm{F}_{\max }$

where $F_{\text {obs }}$ is the fluorescence intensity of thrombin in the presence of the peptide; $F^{0}$ is the initial fluorescence intensity in the absence of the peptide and $\Delta \mathrm{F}_{\max }$ is the maximum change in fluorescence intensity at saturating concentrations of the peptide $\left(\Delta \mathrm{F}_{\max }=\mathrm{F}_{\max }-\mathrm{F}^{0}\right) . \quad \mathrm{F}_{\max }$ was obtained by fitting the fluorescence intensity values to an exponential fit $\left(y=a-b^{*} c^{\wedge} x\right)$ and calculating maximum intensity at limiting concentrations of the individual peptides. This change in fluorescence intensity of thrombin, $\left(\mathrm{F}_{\text {obs }}-\mathrm{F}^{0}\right) / \Delta \mathrm{F}_{\max }$, was then plotted as a function of the individual peptide concentration. The resulting plots were fitted using a nonlinear dose response fit with the hill slope constrained to $\leq 1.3$ in OriginPro 9.1 (OriginLab Corporation, MA, US) to obtain the $K_{d}$ values for the individual peptides.

\section{Confocal microscopy}

$6 \times 10^{6}$ cells (yeast spheroplasts) were washed 3 times in PBS, pH 7.3 by centrifuging at $5,000 \mathrm{x}$ g for $5 \mathrm{~min}$ and the pellet re-suspended in PBS. After fixation with $2 \%$ paraformaldehyde (Sigma Aldrich, St Louis, MO, USA) during 20 min at RT, followed by centrifugation at 5,000 x g for $5 \mathrm{~min}$, spheroplasts were re-suspended in $40 \mu \mathrm{L}$ PBS. The fixed spheroplasts were added to a poly-L-lysine coated slide (Thermo Fisher, Waltham, MA, USA) and allowed to dry for three hours at RT. Slides containing the spheroplasts were washed 3 times in PBS and blocked with PBS containing 5 \% BSA (Sigma Aldrich, St Louis, MO, US) in a wet chamber at $4{ }^{\circ} \mathrm{C}$ for $2 \mathrm{~h}$. Samples were then washed 3 times with PBS and incubated overnight at $4^{\circ} \mathrm{C}$ in a wet chamber with the primary -rabbit anti-human PAR4 antibody APR-034 (Alomone Labs, Jerusalem, Israel) 
that was diluted 1/100 in PBS containing 1\% BSA. After that, samples were washed three times in PBS and incubated with FITC-conjugated goat anti-rabbit IgG (F9887, Sigma Aldrich, St Louis, MO, USA, diluted 1/100 in PBS containing 1\% BSA) for $1 \mathrm{~h}$ 15 min at RT in the dark and mounted with anti-fade reagent Prolong Gold (Molecular Probes, Invitrogen-Life Technologies, Grand Island, NY, US). Two negative controls were used; one without the primary antibody and another one where it was substituted with a non-immune immunoglobulin (negative control rabbit IgG Fraction X0903, DAKO, Copenhagen, Denmark). Images were obtained with the confocal microscope LSM 700 (Carl Zeiss, Stockholm, Sweden) with a 63 x objective.

\section{Results}

\section{Mutation of aspartic acid residues in PAR4 reveal a role for ECLII in receptor activation by thrombin}

We chose the yeast (Saccharomyces cerevisiae) strain MMY12 as the system to express PAR4 and its mutants since this strain was previously used in the expression of many human GPCRs [20], including human PAR1 [21]. Based on previous studies, it appears that the anionic residues of PAR4 play an important role in its interaction with thrombin [16]. Hence, we generated three different mutants of PAR4 where the aspartic residues within the ECLII region were mutated either at a single residue or at multiple residues. In addition, as controls, we generated two single mutants, one at the $\mathrm{N}$-terminal of ECLII and the other in the ECLIII region (Table 1). PAR4 expression was linked to LacZ reporter gene expression, triggering beta-galactosidase activity as a read-out of the receptor activation. This goal was achieved by coupling the expression of a $\mathrm{G}$ protein (engineered in the yeast strain) and PAR4 to the yeast pheromone transduction signal, 
which in turn is coupled to the promoter upstream to the LacZ gene. (MMY12 and primers used are described in supplemental Table 1 and 2). The expression of wtPAR4 and its mutants were confirmed by Western Blot analysis (Supplementary Figure S-1). Furthermore, the location of wtPAR4 on the outer surface of the plasmatic membrane was confirmed by confocal microscopy (Supplementary Figure S-2). To test if the expressed wtPAR4 was functional, we stimulated yeast spheroplasts expressing wtPAR4 with increasing concentrations of $\alpha$ - and $\gamma$-thrombin. We observed that with increasing concentrations of thrombin, there was a corresponding increase in $\beta$ galactosidase activity (Supplementary Figure S-3) thus indicating that the expressed wtPAR4 was functional. Concentrations of $56 \mathrm{nM}$ and $65 \mathrm{nM}$ for $\alpha$ - and $\gamma$-thrombin respectively were chosen for all further experiments. The system also showed specific sensitivity to thrombin inhibition, as the activation by thrombin was attenuated by specific aptamers HD1 and HD22(Supplementary Figures S 7A and S7B), which has previously been shown to block the thrombin exosites I and II, respectively [11]. When we compared the activity of wtPAR4 with those of its mutants, we observed that all PAR4 ECLII mutants showed a significant decrease in their activity (Figure 1). Of these, the double and triple mutants showed the most significant decrease, suggesting an additive effect. Furthermore, the response to the PAR4 activating peptide, PAR4-AP was abolished. The PAR4 N-terminal mutant (D57A+D59A) also showed a significant decrease in activity for thrombin, which is in accordance to what is previously known about the contribution of aspartic residues and the key role of the N-terminal in PAR4 activation. The activity of the mutant D309A whose mutation lies in the ECLIII region, was similar to that of wtPAR4, indicating that the aspartic acid residues in this region are not as important to the activity, as are those in the ECLII region. In addition, the 
results for the PAR4-AP indicate a binding of the new N-terminal of PAR4, created by cleavage by thrombin, to ECLII.

Since PAR receptors are activated upon the cleavage of its N-terminal by thrombin, we wanted to check if the decrease in activity observed for the PAR4 mutants was due to $\alpha$ thrombin's inability to cleave them. Western Blot analysis using an antibody specific for the non-cleaved PAR4 N-terminal showed that the cleavage of double and triple mutants by $\alpha$-thrombin was attenuated (Figure 2). These results suggest that PAR4 cleavage is facilitated by interactions between $\alpha$-thrombin and the aspartic residues in ECLII.

\section{Peptides mimicking PAR4 ECLII and N-terminal affect responses to thrombin in}

\section{human platelets}

After confirming the importance of the aspartic residues 224, 230 and 235 at ECLII of human PAR4 in a eukaryotic model, we investigated the importance of these residues in the activation of human platelets. To do this, we employed three short peptides (13-17 aa in length) representing regions of PAR4 containing the key aspartic acids identified in the mutation experiments. While one of the peptide sequences represented the $\mathrm{N}$ terminal region, the other two represented the ECLII region. The peptide sequences were selected keeping in mind their stability (calculated index in solution, sequences are listed in Table 2). The potential of the peptides to affect thrombin activation of human platelets was assessed by flow cytometry. Platelet activation was measured as expressed P-selectin (Figure 3A-B) or the active state of fibrinogen receptor GPIIb/IIIa using the specific monoclonal antibody PAC-1 (Figure 3C-D). A dose-dependent inhibition was observed when $\gamma$-thrombin was used to activate platelets (Figure 3A, 3C). For $\alpha$ thrombin, only marginal, if any, effects were seen (Figure 3B, 3D). The peptides had no 
significant effect on thrombin activity on a fluorogenic substrate (supplementary Figure S-4A and B). Similar effects were found in platelet aggregation measured by light transmittance aggregometry (Figure 4), once more, a potent inhibition of $\gamma$-thrombininduced aggregation was observed, but at high final concentrations of peptides (1000 $\mu \mathrm{M})$, a decrease in platelet aggregation was seen for $\alpha$-thrombin as well. As the results for peptides 224-235 and 223-239 were relatively similar, the difference in stability did not seem to cause problems in these settings. To investigate the possibility that the concentration of peptide per se could be the cause of attenuation of aggregation, we performed a set of experiments with a pseudo 223-239 peptide (see Table 2, with similar properties to the ECLII peptides, considering number of amino acids, molecular weight and pI, but lacking the electronegative amino acids proposed to be causing the observed effects) at the same working concentration. The P-selectin expression in response to $20 \mathrm{nM} \gamma$-thrombin was $69.3 \pm 12.3 \%$ in the absence and $65.7 \pm 18.5 \%$ in the presence of $600 \mu \mathrm{M}$ of this scrambled peptide (mean $\pm S D, n=4$ ). This, together with the lack of any significant difference in platelet activation in the presence of this peptide (Figure 3A, 3C and 4) leads us to conclude that the observed effects with the ECLII peptides are due to their specific amino acid sequence.

We further investigated whether these results were caused by a decreased $\mathrm{N}$-terminal cleavage of PAR4, by using the same N-terminal-specific antibody as in the yeast model. Indeed, the decrease in the PAR4 band upon thrombin activation was less pronounced in the presence of the peptides (supplemental Figure S-5). The N-terminal and thus also the 55-67 peptide is expected to bind to exosite I, thus affecting cleavage by both $\alpha$-thrombin and $\gamma$-thrombin. The 223-239 peptide is affecting cleavage less by $\alpha$-thrombin than by $\gamma$-thrombin since the latter lacks exosite I, making the exosite II more important for binding to PAR4 and more easily occupied by the 223-239 peptide. 
However, cross-interactions are unavoidable due to the electrostatic similarities of the peptides.

\section{Specificity for PAR4}

To check that the peptides were specifically affecting thrombin-induced PAR4 activation, we confirmed that they did not affect platelet activation by ADP in flow cytometry (supplementary Figure S-6) or aggregometry. In addition, they did not affect the proteolytic activity of thrombin (supplementary Figure S-4A and B). We also confirmed that the thrombin cleavage of the PAR4 receptor or the platelet activation responses in the presence of peptides were not affected by the presence of the PAR1inhibitor SCH-79797 (data not shown).

Additional support for this specificity was found when we added the exosite I and II blocking aptamers HD1 and HD22 together with the peptides (supplemental Figure S7A and B). Interestingly, the addition of the exosite II blocker and peptides almost abrogated PAR 4 cleavage by $\gamma$-thrombin (supplemental Figure S-7A), suggesting a specific focus on exosite II for the ECLII peptide.

\section{Tryptophan fluorescence studies of PAR4 peptides binding to $\gamma$-thrombin.}

In order to confirm the binding of the synthetic PAR4 peptides (223-239, 224-235 and 55-67) to thrombin, we monitored the change in intrinsic tryptophan fluorescence of $\gamma$ thrombin upon addition of these peptides. This information was used to determine the apparent $K_{d}$ values for the individual peptide binding, which were estimated to be 0.41 $\pm 0.06 \mathrm{mM}, 0.16 \pm 0.02 \mathrm{mM}$ and $0.51 \pm 0.13 \mathrm{mM}$ for 223-239, 224-235 and 55-67 peptides respectively (Figure 5). The peptides screened for their binding to $\gamma$-thrombin contained no tryptophan residues and hence, any change in fluorescence intensity can be directly attributed to those arising from thrombin. Control experiments with pseudo 
223-229 peptide yielded no significant change in the overall tryptophan fluorescence even at saturating concentrations of the peptide (Supplementary Figure S-8). HD1 and HD22, which block the exosites and are otherwise good controls could not be used in these experiments due to inner filter effects.

\section{Discussion}

The activation of PAR1 by thrombin has been studied in detail, including structural information obtained from crystallography [14]. These studies could confirm previous reports stating that ECLII is the binding site for the new N-terminal formed after cleavage by thrombin [15]. Based on the sequence homology between PAR4 and PAR1, and the conserved pair of cysteines in the ECLII allowing a key disulphide bridge, it could be expected that the ECLII played a role for PAR4 activation as well. If present, this interaction would add to the well-known function of the N-terminal for thrombin binding and receptor activation.

We recently reported that exosite II in thrombin was critical for activation of PAR4 and that this interaction was unaffected by blockage of the previously known interaction between thrombin and GpIb $\alpha$ [17]. These findings are supported by a previous study where introduction of the mutation W215A in thrombin exosite II reduced PAR4 cleavage 280-fold and increased $\mathrm{K}_{\mathrm{d}}$ 800-fold for PAR4 but no changes at all for PAR1 [18]. The mutated tryptophan in thrombin could be involved in the stability of the structure of exosite II as it is a key amino acid in several hydrogen bridges [6]. In addition, it may also be involved in hydrophobic interactions, which might be of relevance for the interaction with PAR4. 
PAR4 contains a cluster of electronegative residues in the ECLII, with aspartic residues in positions 224, 230 and 235, and another cluster at positions 57, 59 and 66 in the Nterminal. The interaction between a peptide from the PAR4 N-terminal with exosite I in thrombin has been described [22], this is another evidence that lead us to believe that we could expect to find similar effects in the interaction with exosite II, due to the electrostatic similarities between exosite I and II [23], and the confirmed importance of anionic residues for the interaction with exosites [16]. Although the data from Bah et al [22] depicts and demonstrates a clear interaction only with exosite I, an alternative interaction with exosite II cannot be discarded, as their study was exclusively made with peptides mimicking $\mathrm{N}$-terminal areas and was focused on the interaction with exosite I.

We suspected that electronegative amino acids in ECLII of PAR4 could be important for its interaction with thrombin, in analogy with the ECLII in PAR1 [16]. To test this hypothesis, we induced the expression of human wtPAR4 and several mutants of interest in a yeast model. Indeed, we found that the activation of PAR4 by thrombin was abolished in the triple ECLII mutant (D224A, D230A, D235A) and attenuated in the single D224A and the double mutant (D230A, D235A) but not attenuated in the single ECLIII mutant, D309A. When y-thrombin (a proteolytic product of $\alpha$-thrombin, which lacks exosite I) was used as activator, the effects of the ECLII mutations were more pronounced than when using $\alpha$-thrombin, which speaks in favour of an interaction between exosite II and ECLII. In accordance with previous studies [22], mutations in the N-terminal attenuated the response to both types of thrombin. Furthermore, the response to PAR4-AP was also abolished in the triple mutant and attenuated much like thrombin in the other mutations, with the important exception of mutations in the $\mathrm{N}$ terminal of PAR4. This suggests ECLII as the binding site for the new N-terminal formed after thrombin cleavage. 
To test our findings in the more physiological context of platelet activation, we used peptides mimicking the parts with electronegative clusters in the N-terminal and in ECLII to study potential inhibiting effects on thrombin activation of human platelets. None of the peptides had much effect on platelet activation by $\alpha$-thrombin, measured as fibrinogen receptor activation or P-selectin expression utilizing flow cytometry, but the response to $y$-thrombin was attenuated (Figure 3). A possible explanation is that in platelets, activation through PAR1 by $\alpha$-thrombin can induce almost maximal activation, while activation by y-thrombin may be more dependent on PAR4. However, in light transmission aggregometry, the peptides at $1 \mathrm{mM}$ had a clear effect also on responses to $\alpha$-thrombin and almost abolished responses to y-thrombin (Figure 4). A limitation is the high concentrations of peptides used, but we could demonstrate that the peptides had no effects on activation by ADP (Supplementary Figure S-6) and that the control peptide pseudo 223-239 had no inhibitory effects on $\gamma$-thrombin activation (Figure 3).

The change in fluorescence intensity of $\gamma$-thrombin upon peptide binding was measured and used to estimate the strength of the binding of the peptides to thrombin (Figure 5). The results indicate a relatively weak binding, but as the apparent Kd values were determined indirectly, these results are only useful as an indicator of peptide affinity and specificity to thrombin, and therefore they might not fully reflect their potential effects in the platelet experiments. Human $\gamma$-thrombin contains 9 tryptophan residues and due to the existence of multiple tryptophan residues on $\gamma$-thrombin, it is difficult to ascertain which residues are directly affected by peptide binding or the exact binding location of the peptides to thrombin. 
The large impact seen for PAR4 mutants in the yeast model must be interpreted with caution, as yeast cells are lacking other GPCR pathways that would potentially modulate the extent of responses in other cells such as platelets. In addition, the role for these domains in the formation of receptor homo- and heterodimers (with PAR1) has not been investigated, but might be a future area of investigation in this field.

In conclusion, our results support a role for the aspartic residues of ECLII in thrombin binding and activation of PAR4 and suggest that the docking site for the new Nterminus unmasked by thrombin cleavage is situated in ECLII. Our results also suggest that ECLII is involved in direct interaction with thrombin, with exosite II as the probable counterpart, in analogy to the previously described mechanism for thrombin interaction with PAR1.

\section{Acknowledgements}

This study was supported by a grant from the Swedish Research Council, Project NoK2013-65X-15060-10-3 and the Swedish Heart-Lung foundation, project No 20140410. Help with figures by Maria Wallstedt and with thrombin generation assays by Lars Faxälv is gratefully acknowledged. 


\section{References}

[1] Kahn ML, Zheng YW, Huang W, Bigornia V, Zeng D, Moff S, et al. A dual thrombin receptor system for platelet activation. Nature. 1998;394:690-4.

[2] Shapiro MJ, Weiss EJ, Faruqi TR, Coughlin SR. Protease-activated receptors 1 and 4 are shut off with distinct kinetics after activation by thrombin. J Biol Chem. 2000;275:25216-21.

[3] Jonnalagadda D, Izu LT, Whiteheart SW. Platelet secretion is kinetically heterogeneous in an agonist-responsive manner. Blood. 2012;120:5209-16.

[4] Vretenbrant K, Ramstrom S, Bjerke M, Lindahl TL. Platelet activation via PAR4 is involved in the initiation of thrombin generation and in clot elasticity development. Thromb Haemost. 2007;97:417-24.

[5] Falker K, Haglund L, Gunnarsson P, Nylander M, Lindahl TL, Grenegard M. Protease-activated receptor 1 (PAR1) signalling desensitization is counteracted via PAR4 signalling in human platelets. Biochem J. 2011;436:469-80.

[6] Bode W, Turk D, Karshikov A. The refined 1.9-A X-ray crystal structure of D-PhePro-Arg chloromethylketone-inhibited human alpha-thrombin: structure analysis, overall structure, electrostatic properties, detailed active-site geometry, and structurefunction relationships. Protein Sci. 1992;1:426-71.

[7] Li CQ, Vindigni A, Sadler JE, Wardell MR. Platelet glycoprotein Ib alpha binds to thrombin anion-binding exosite II inducing allosteric changes in the activity of thrombin. J Biol Chem. 2001;276:6161-8.

[8] Zarpellon A, Celikel R, Roberts JR, McClintock RA, Mendolicchio GL, Moore KL, et al. Binding of alpha-thrombin to surface-anchored platelet glycoprotein Ib(alpha) sulfotyrosines through a two-site mechanism involving exosite I. Proc Natl Acad Sci U S A. 2011;108:8628-33.

[9] Lechtenberg BC, Freund SM, Huntington JA. GpIbalpha interacts exclusively with exosite II of thrombin. J Mol Biol. 2014;426:881-93.

[10] Sheehan JP, Sadler JE. Molecular mapping of the heparin-binding exosite of thrombin. Proc Natl Acad Sci U S A. 1994;91:5518-22.

[11] Nimjee SM, Oney S, Volovyk Z, Bompiani KM, Long SB, Hoffman M, et al. Synergistic effect of aptamers that inhibit exosites 1 and 2 on thrombin. RNA. 2009;15:2105-11.

[12] Jacques SL, Kuliopulos A. Protease-activated receptor-4 uses dual prolines and an anionic retention motif for thrombin recognition and cleavage. Biochem $\mathrm{J}$. 2003;376:733-40.

[13] Leger AJ, Jacques SL, Badar J, Kaneider NC, Derian CK, Andrade-Gordon P, et al. Blocking the protease-activated receptor 1-4 heterodimer in platelet-mediated thrombosis. Circulation. 2006;113:1244-54.

[14] Zhang C, Srinivasan Y, Arlow DH, Fung JJ, Palmer D, Zheng Y, et al. Highresolution crystal structure of human protease-activated receptor 1 . Nature. 2012;492:387-92.

[15] Blackhart BD, Ruslim-Litrus L, Lu CC, Alves VL, Teng W, Scarborough RM, et al. Extracellular mutations of protease-activated receptor-1 result in differential 
activation by thrombin and thrombin receptor agonist peptide. Mol Pharmacol. 2000;58:1178-87.

[16] Nieman MT. Protease-activated receptor 4 uses anionic residues to interact with alpha-thrombin in the absence or presence of protease-activated receptor 1. Biochemistry. 2008;47:13279-86.

[17] Boknas N, Faxalv L, Sanchez Centellas D, Wallstedt M, Ramstrom S, Grenegard $\mathrm{M}$, et al. Thrombin-induced platelet activation via PAR4: pivotal role for exosite II. Thromb Haemost. 2014;112:558-65.

[18] Arosio D, Ayala YM, Di Cera E. Mutation of W215 compromises thrombin cleavage of fibrinogen, but not of PAR-1 or protein C. Biochemistry. 2000;39:8095101.

[19] Gietz D, St Jean A, Woods RA, Schiestl RH. Improved method for high efficiency transformation of intact yeast cells. Nucleic Acids Res. 1992;20:1425.

[20] Dowell SJ, Brown AJ. Yeast assays for G-protein-coupled receptors. Receptors Channels. 2002;8:343-52.

[21] Swift S, Sheridan PJ, Covic L, Kuliopulos A. PAR1 thrombin receptor-G protein interactions. Separation of binding and coupling determinants in the galpha subunit. $\mathrm{J}$ Biol Chem. 2000;275:2627-35.

[22] Bah A, Chen Z, Bush-Pelc LA, Mathews FS, Di Cera E. Crystal structures of murine thrombin in complex with the extracellular fragments of murine proteaseactivated receptors PAR3 and PAR4. Proc Natl Acad Sci U S A. 2007;104:11603-8.

[23] Richardson JL, Kroger B, Hoeffken W, Sadler JE, Pereira P, Huber R, et al. Crystal structure of the human alpha-thrombin-haemadin complex: an exosite II-binding inhibitor. EMBO J. 2000;19:5650-60. 


\section{Tables}

Table 1. Human PAR4 mutants used in this work, generated by site directed mutagenesis and expressed in yeast. Double and triple mutants were generated sequentially.

\begin{tabular}{|c|c|c|}
\hline Mutant & Residue mutated & Region involved \\
\hline $\begin{array}{c}\text { D57A } \\
\text { D59A }\end{array}$ & $\begin{array}{l}\text { Asp 57 to Ala } \\
\text { Asp 59 to Ala }\end{array}$ & N-terminal \\
\hline D224A & Asp 224 to Ala & ECLII \\
\hline $\begin{array}{c}\text { D230A } \\
\text { D235A }\end{array}$ & $\begin{array}{l}\text { Asp 230 to Ala } \\
\text { Asp 235to Ala }\end{array}$ & ECLII \\
\hline Triple mutant & $\begin{array}{l}\text { Asp 224 to Ala } \\
\text { Asp 230 to Ala } \\
\text { Asp 235to Ala }\end{array}$ & ECLII \\
\hline D309A & Asp 309 to Ala & ECLIII \\
\hline
\end{tabular}

Table 2. Peptides used to study inhibition of thrombin activation of platelets. Each peptide is named by their amino acid number in the sequence of PAR4.

\begin{tabular}{|c|c|c|c|c|c|c|c|}
\hline Peptide & $\begin{array}{c}\text { MW } \\
\text { (Da)* }\end{array}$ & pI & $\begin{array}{c}\text { Length } \\
\text { (aa) }\end{array}$ & $\boldsymbol{\varepsilon}$ & $\begin{array}{c}\text { Aliphatic } \\
\text { index }\end{array}$ & $\begin{array}{c}\text { Instability } \\
\text { index }\end{array}$ & Sequence \\
\hline $55-67$ & 1407 & 3.37 & 13 & 0 & 67.69 & 46.1 unstable & ANDSDTLELPDSS \\
\hline $223-239$ & 1854.0 & 4.41 & 17 & 0 & 103.53 & $\begin{array}{c}51.13 \\
\text { unstable }\end{array}$ & SDRVLCHDALPLDAQAS \\
\hline $224-235$ & 1407.5 & 4.41 & 12 & 0 & 130 & 35.38 stable & DRVLCHDALPLD \\
\hline $\begin{array}{c}\text { Pseudo } \\
223-239\end{array}$ & 1895.2 & 5.24 & 18 & 0.17 & & & SAMVLTYNALNTQAIMGP \\
\hline
\end{tabular}

*Considering $\mathbf{N}$-terminal acetylation 


\section{Figure legends}

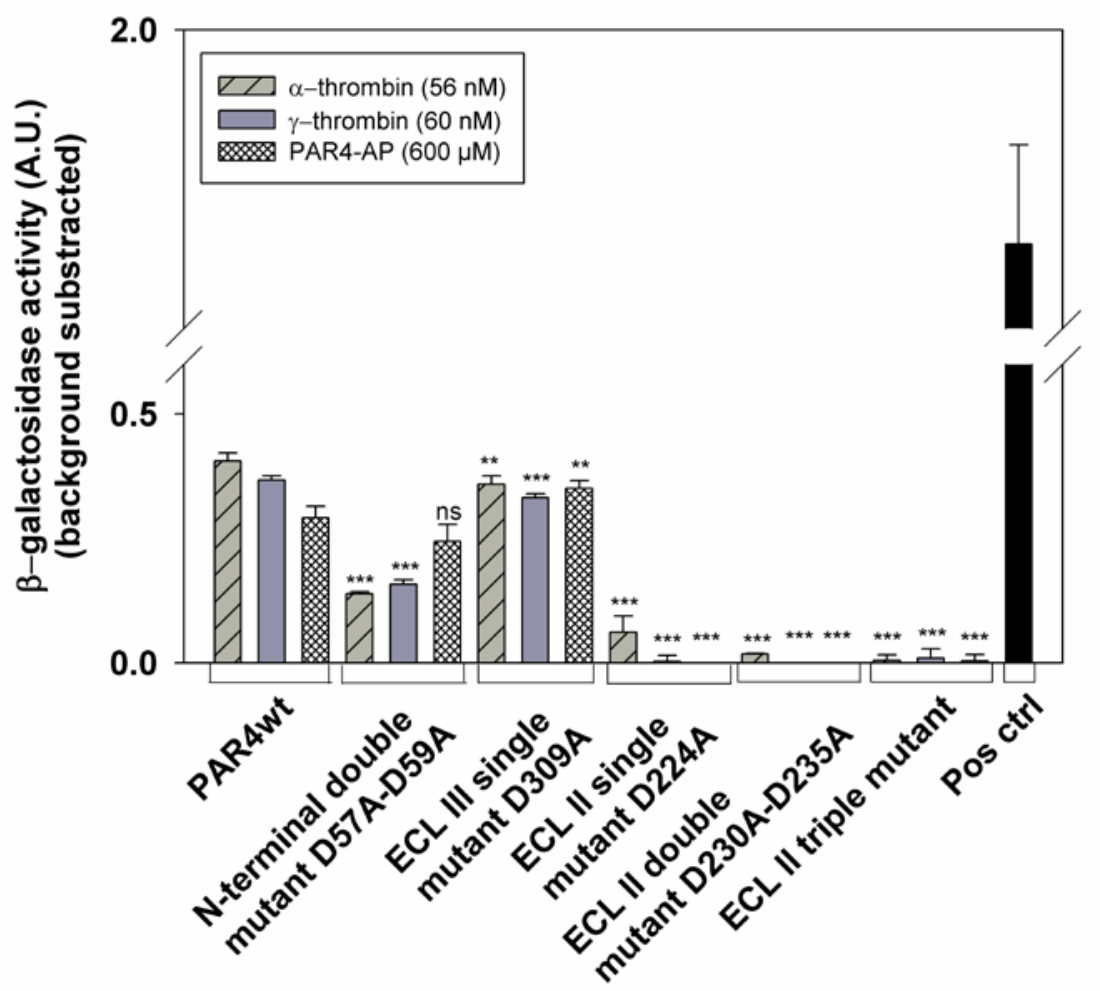

Figure 1. Activation of wtPAR4 and mutants expressed in yeast induces the Lac $Z$ gene and subsequently beta-galactosidase activity, but less in ECLII and Nterminal mutants. Effects of five different variants of aspartic mutations in PAR4 compared with wtPAR4. Very little activation was seen in double or triple mutants in ECLII with varying degree of activation of other mutants with $\alpha$-thrombin (56 nM), $\gamma^{-}$ thrombin $(60 \mathrm{nM})$ or PAR4-activating peptide $(600 \mu \mathrm{M})$. MMY12 transformed with a constitutively expressed GPCR stimulated with NECA was used as LacZ positive control. The bars show mean+SD from six absorbance measurements with each activator in different yeast preparations. The background, i.e. the signal with no agonist for each yeast preparation, was subtracted. Significance was calculated vs the response in wtPAR4 for each agonist, T-test, ${ }^{* *} \mathrm{p}<0.01,{ }^{* * *} \mathrm{p}<0.001$. 


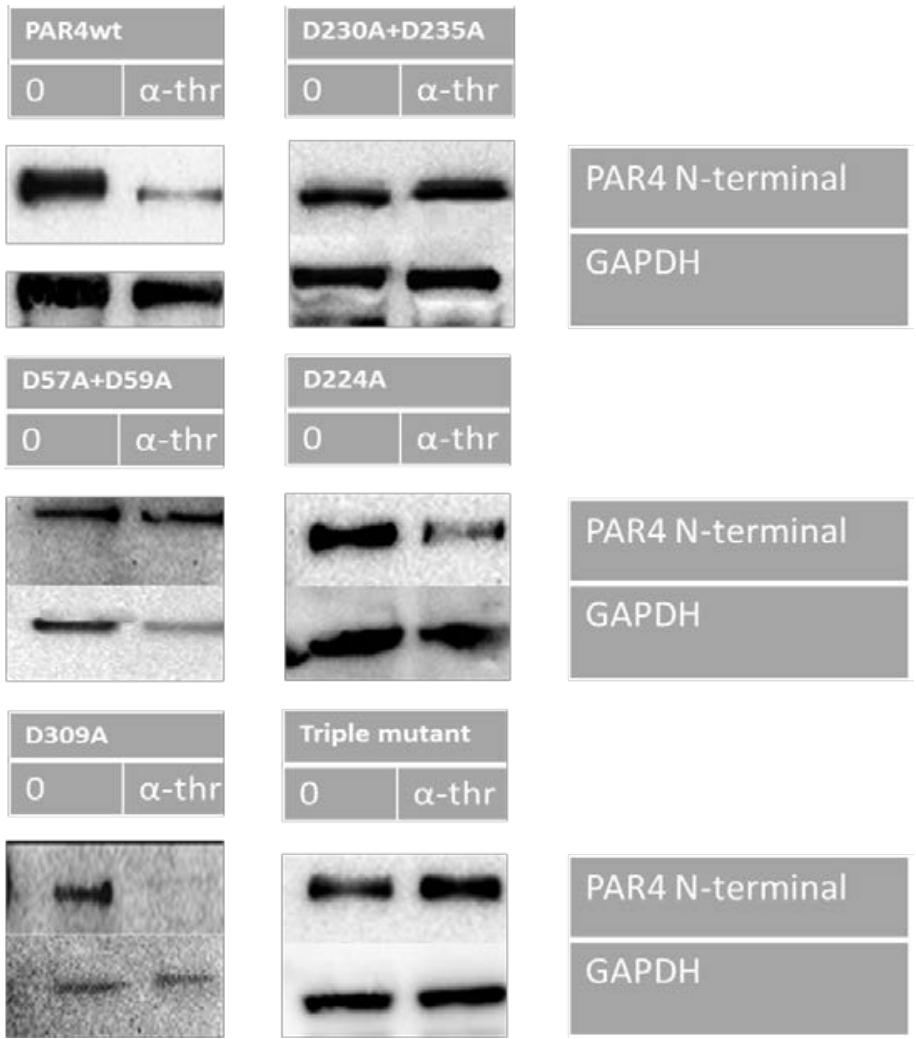

Figure 2. Thrombin-induced PAR4 cleavage is attenuated in D to A mutants in

ECLII. Yeast lysate was incubated with $\alpha$-thrombin (56 nM). PAR4 was visualized with antibodies directed towards the PAR4 N-terminal region. 0 is non-treated yeast spheroplasts. GAPDH was used as loading control (lower 
band).
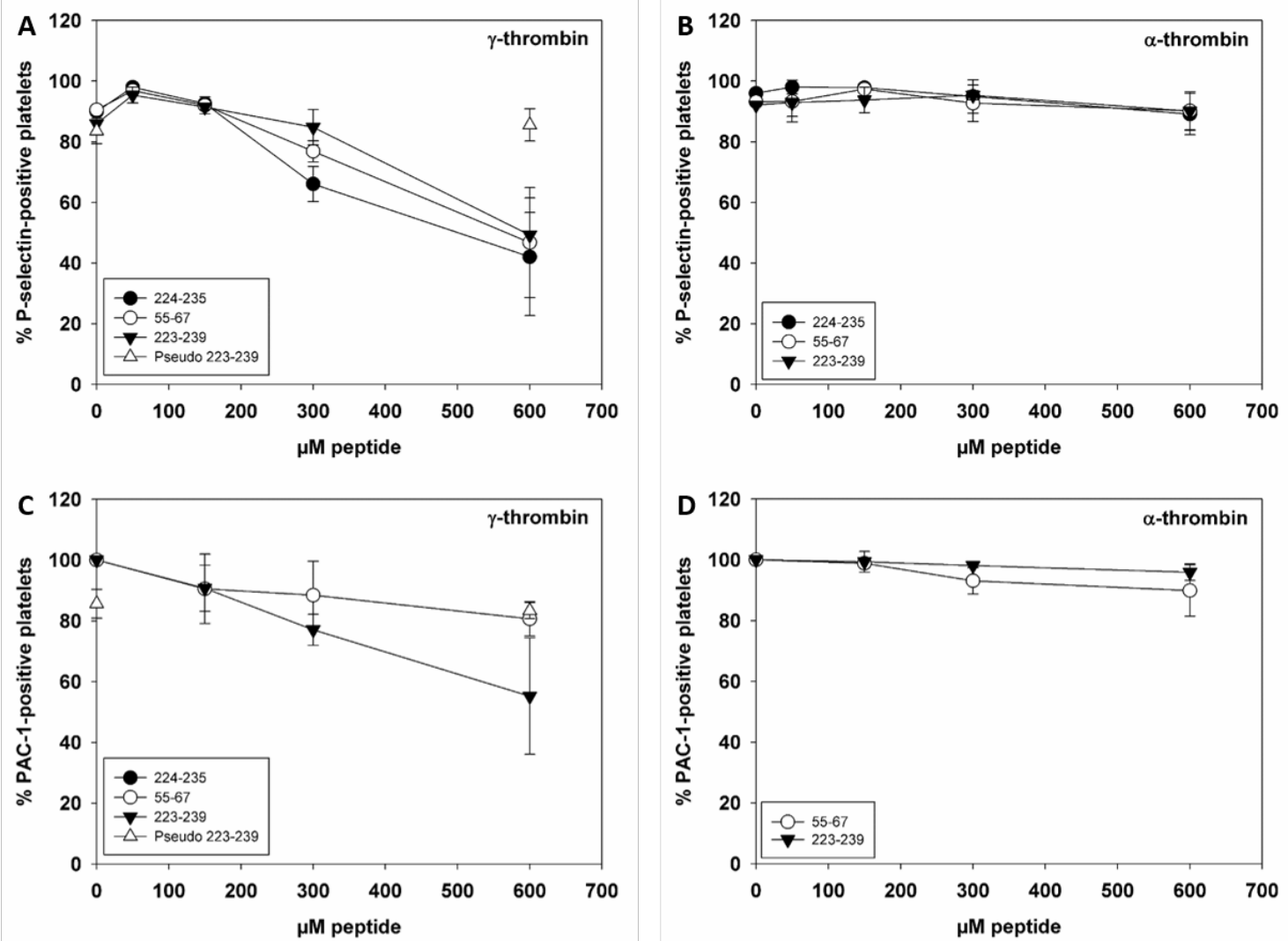

Figure 3. Peptides representing PAR4 ECLII and N-terminal attenuate $\gamma$-thrombin induced platelet activation more than $\alpha$-thrombin induced activation. Activation of platelets by $\gamma$-thrombin (20 nM) (A and C) or $\alpha$-thrombin (14 nM) (B and D), which are equipotent in terms of platelet activation. Platelet activation was measured by flow cytometry as P-selectin expression (A and B) or fibrinogen receptor activation by binding of the MoAb PAC-1 (C and D). Concentration of peptide is shown on the $\mathrm{x}$-axis (mean \pm SD, $n=3$ ). The pseudo 223-239 was only run for $\gamma$-thrombin, at $600 \mathrm{nM}$. 
A

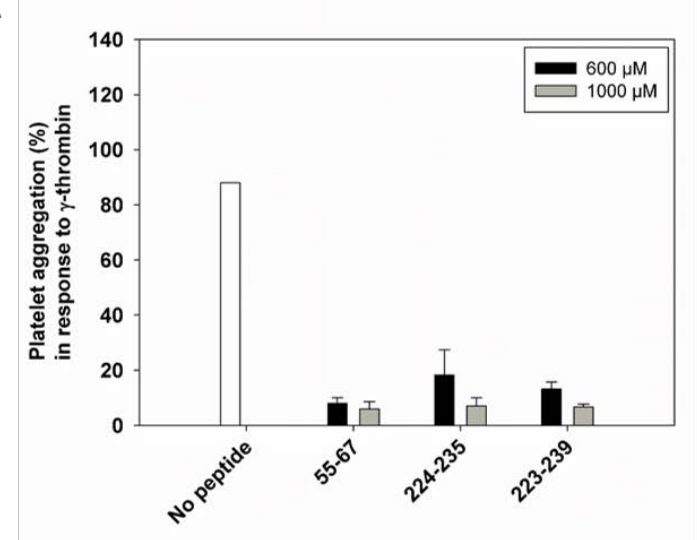

C

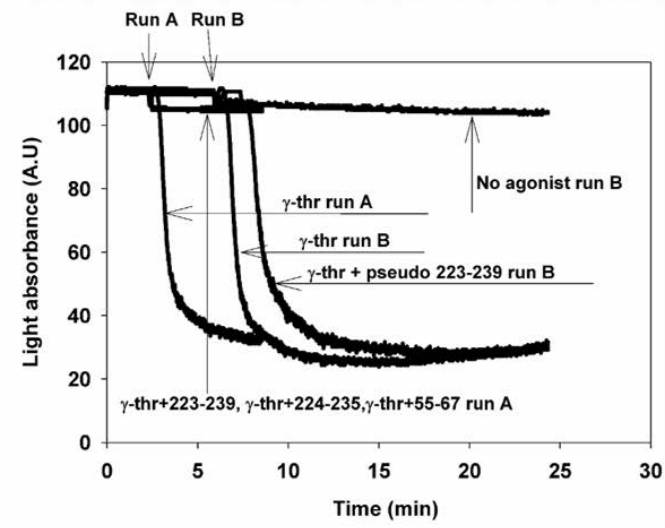

B

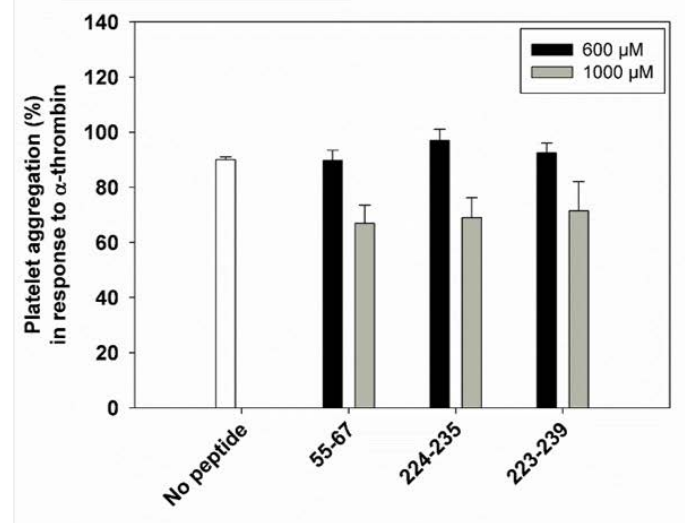

D

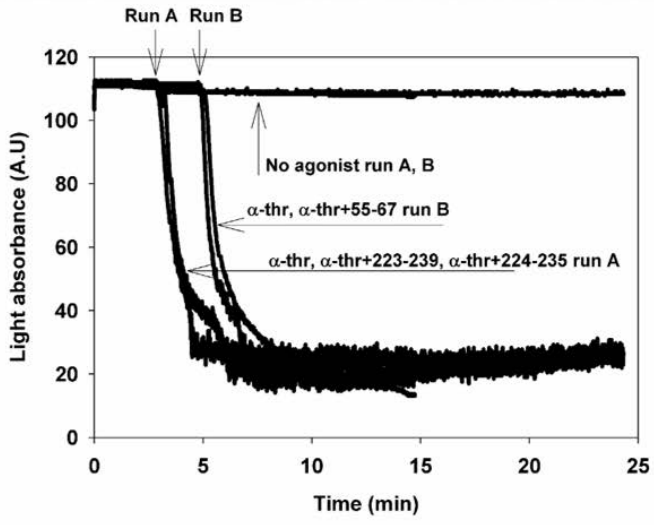

Figure 4. Peptides representing PAR4 ECLII and N-terminal strongly attenuate $\gamma$ thrombin-induced platelet aggregation, but show little effect on $\alpha$-thrombininduced aggregation. A-B) Platelet aggregation in response to A) $\gamma$-thrombin (40 nM) and B) $\alpha$-thrombin (14 $\mathrm{nM}$ ), peptide concentrations 600 or $1000 \mu \mathrm{M}$ as indicated (mean+SD, n=2-3). C-D) aggregometry curves from one donor showing responses to $\mathrm{C}$ ) $\gamma$-thrombin (40 nM), and D) $\alpha$-thrombin (14 nM) in presence of $600 \mu \mathrm{M}$ of the indicated peptides. To enable comparisons between all peptides in the same graph, they display merged raw data for light absorbance (in arbitrary units) from the Chronolog instrument from two consecutive runs. Arrows show the time for thrombin addition for the different runs. 


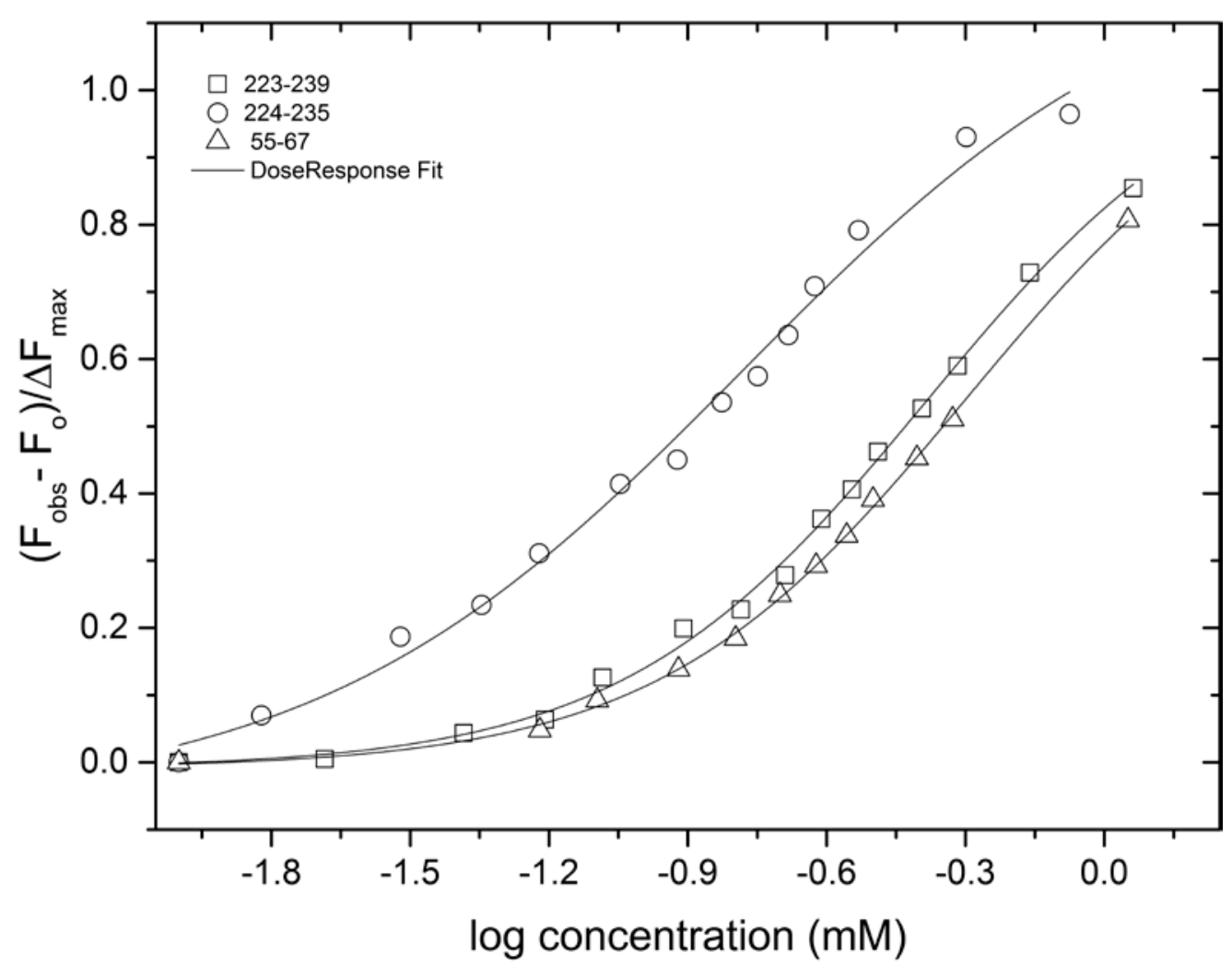

Figure 5. Binding of PAR4 peptides to $\gamma$-thrombin. Fractional change in fluorescence intensity of $\gamma$-thrombin upon peptide binding is plotted as a function of individual peptide concentrations. The plots were fitted using a non-linear dose response curve and the apparent $K_{d}$ values were estimated for 223-239, 224-235 and 55-67 peptides to be $0.41 \pm 0.06 \mathrm{mM}, 0.16 \pm 0.02 \mathrm{mM}$ and $0.51 \pm 0.13 \mathrm{mM}$ respectively. 
SUPPLEMENTAL MATERIAL

\section{Figures}

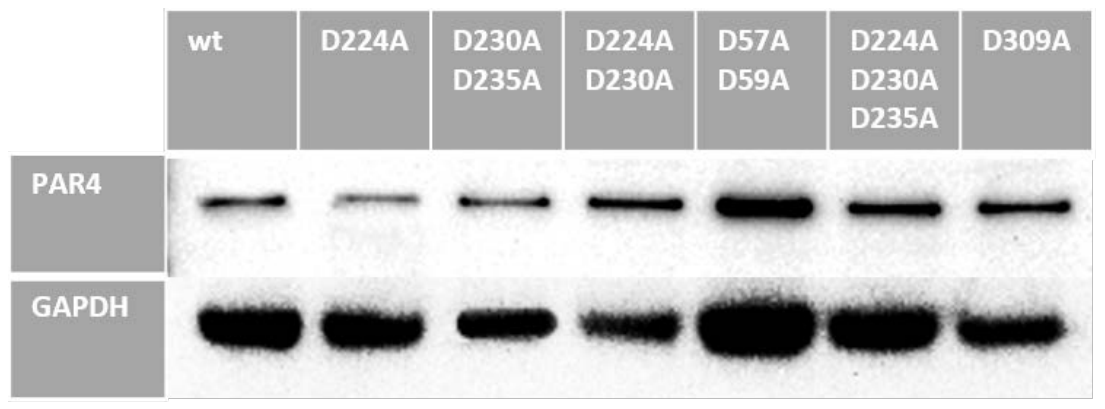

Figure S-1. PAR4 expressed in yeast. Western blot show PAR4 in yeast strain MMY12 expressing wtPAR4 and six PAR4 mutants, amino acid substitutions as indicated. PAR4 was visualized with a monoclonal antibody directed against the PAR4 $\mathrm{N}$-terminal region. GAPDH was used as loading control (lower band).

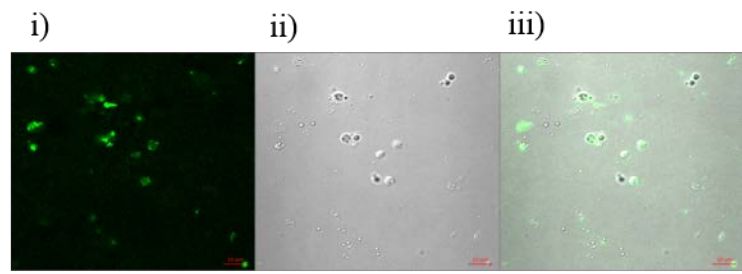

B

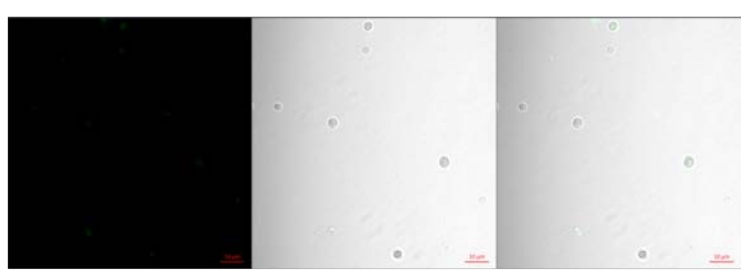

$\mathrm{C}$

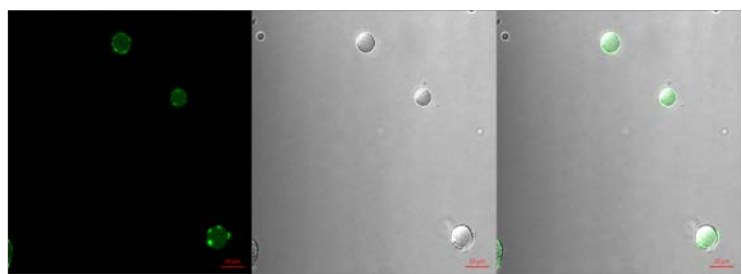

Figure S-2. Confocal micrograph immunolocation of PAR4 on yeast spheroplasts. A) MMY12 expressing wtPAR4, B) Non-transformed MMY12 C) MMY12 expressing PAR4 D224A. Magnification x63, i) fluorescence view, ii); differential interference contrast (DIC) view iii) merge of i) and ii). 


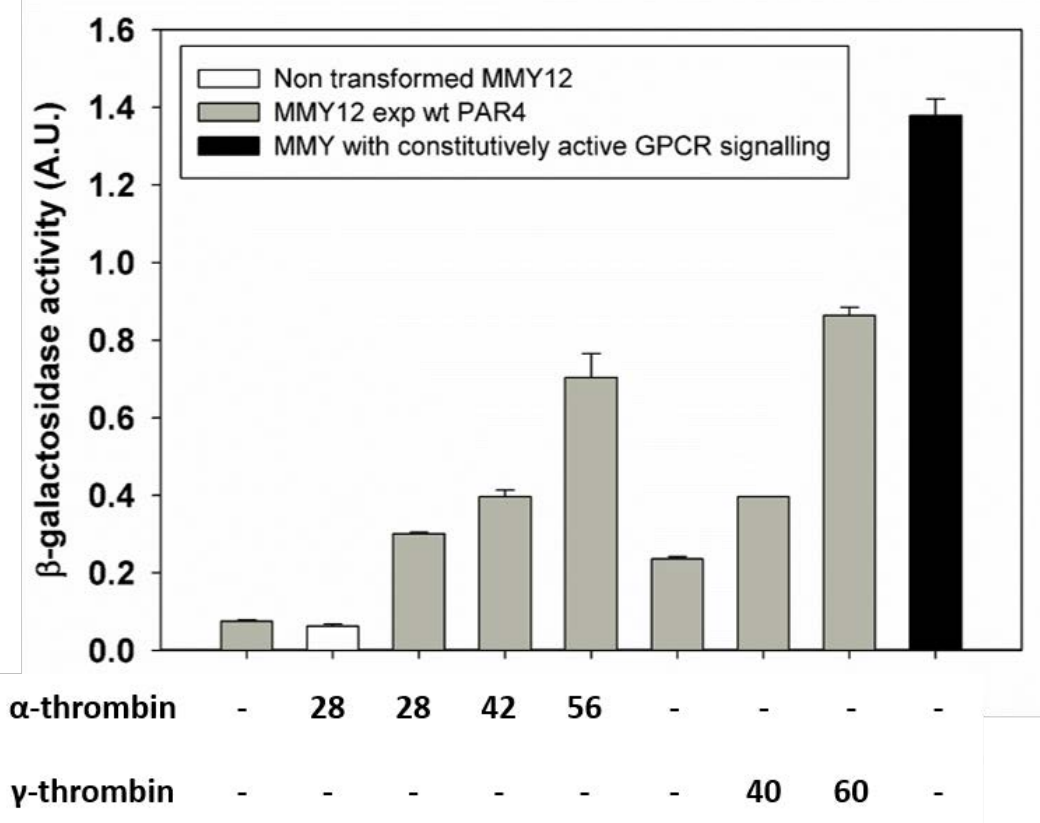

Figure S-3. Activation of wtPAR4 expressed in yeast induces the Lac $\mathrm{Z}$ gene and subsequently beta-galactosidase activity. Effects of activation of yeast transformed with wtPAR4 with increasing concentrations of $\alpha$-thrombin or $\gamma$-thrombin. The white bar shows not transformed yeast incubated with $28 \mathrm{nM} \alpha$-thrombin. MMY12 transformed with a constitutively expressed GPCR stimulated with NECA was used as Lac $\mathrm{Z}$ positive control (black bar). The bars show mean+SD n=6.
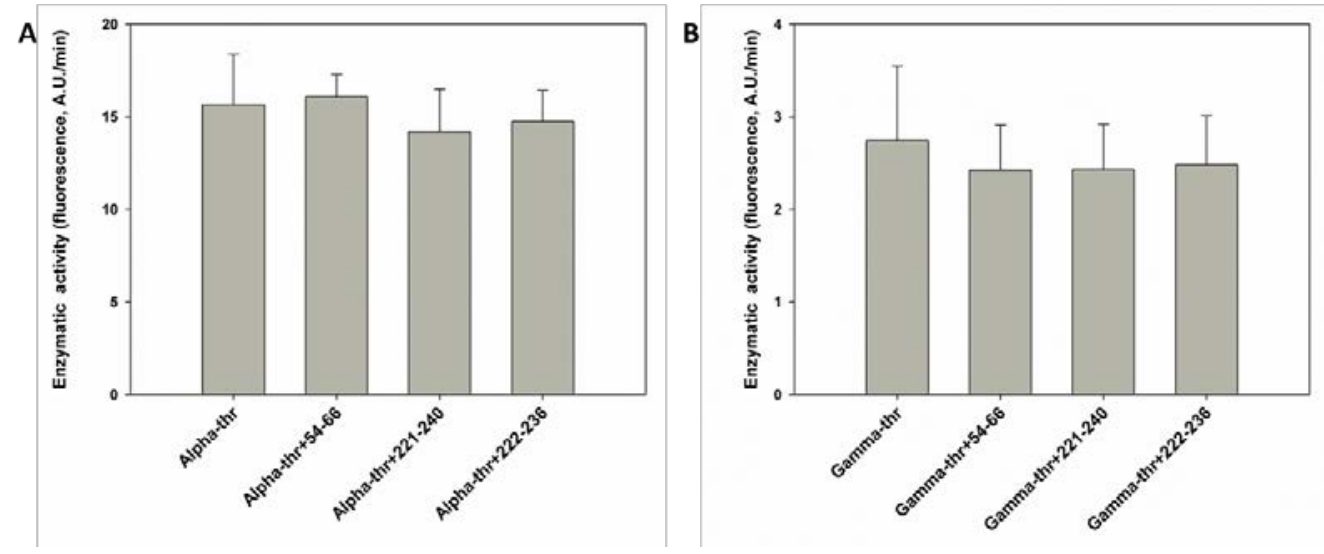

Figure S-4. Peptides mimicking PAR4 ECLII and N-terminal do not affect

thrombin enzymatic activity. The peptides, final concentration $600 \mu \mathrm{M}$, had no significant effect on the enzymatic activity of A) $\alpha$-thrombin, $14 \mathrm{nM}$, or B) $\gamma$-thrombin, $20 \mathrm{nM}$, as measured as cleavage of the fluorescent substrate Z-Gly-Gly-Arg-AMC at $0.4 \mathrm{mM}$. 


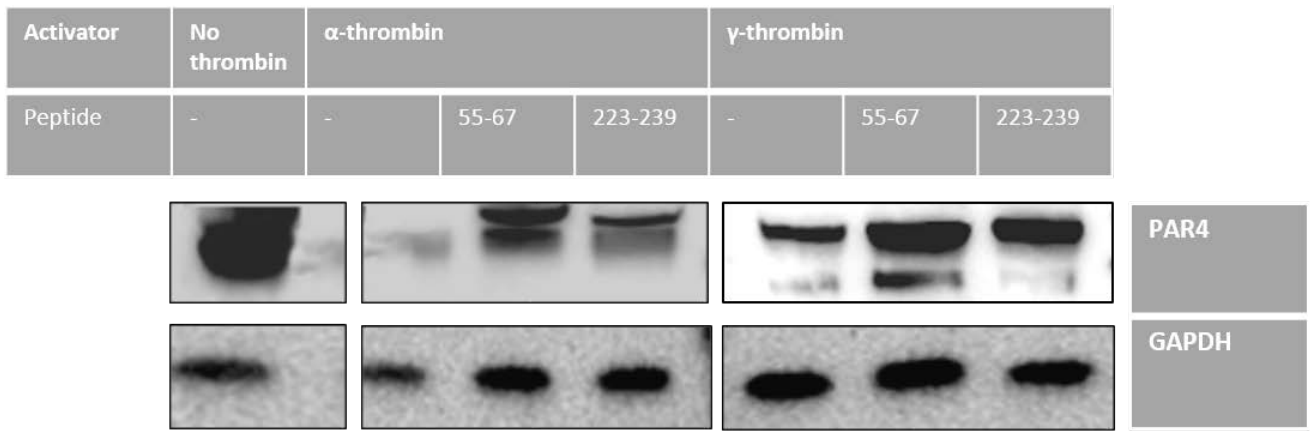

Figure S-5. Evaluation of peptide specificity for thrombin exosites using different types of thrombin. Effects on thrombin-induced cleavage of platelet PAR4 by peptides visualized by a monoclonal antibody against the N-terminal of PAR4. Concentration of thrombin is $14 \mathrm{nM}, \gamma$-thrombin $20 \mathrm{nM}$, peptides at $600 \mu \mathrm{M}$. Different combinations of effectors over platelets are described in the corresponding lane in the figure. Detection of GAPDH with a mouse monoclonal antibody against yeast GAPDH was used as loading control (lower band).

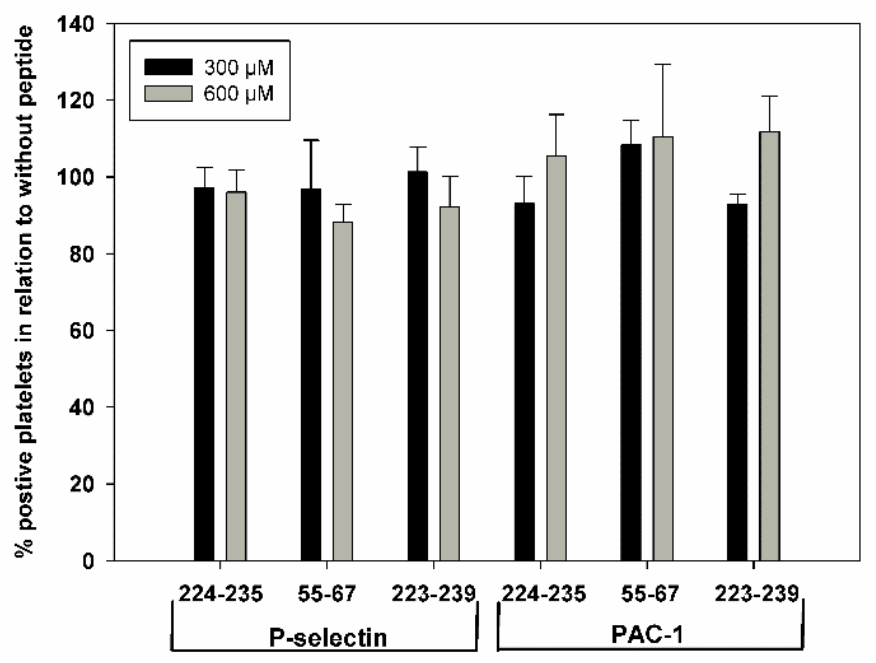

Figure S-6. Evaluation of peptide specificity by measuring effect on activation by ADP. Platelets were activated by ADP $10 \mu$. Platelet activation was measured by flow cytometry as P-selectin expression or fibrinogen receptor activation by binding of the MoAb PAC-1 as percentage positive platelets. The graph shows results in relation to the sample without peptide, which was assigned a value of $100 \%$. 

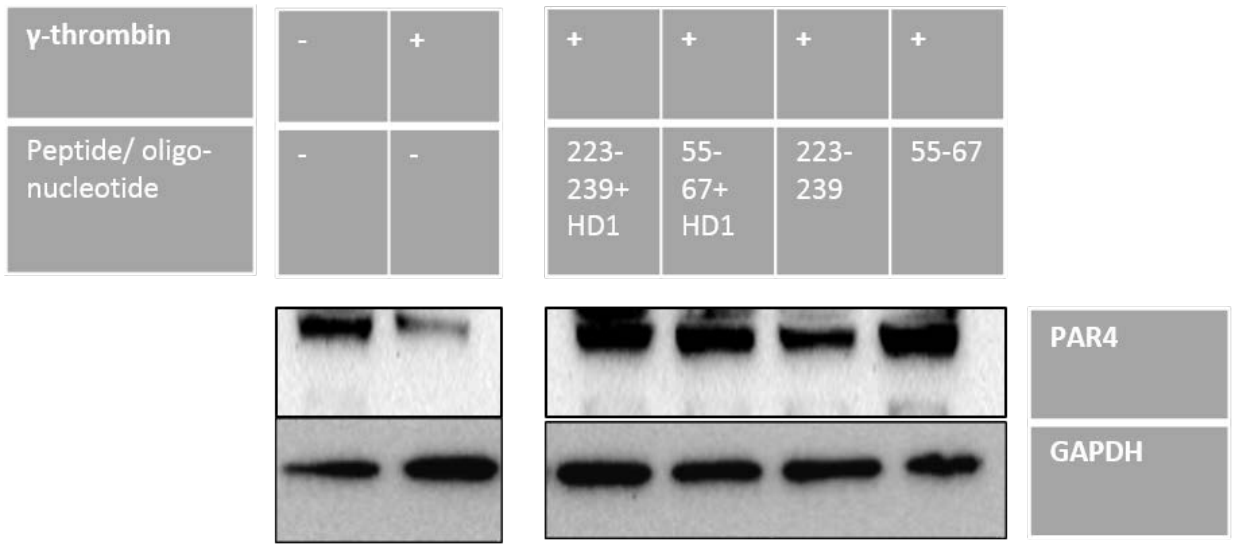

Figure S-7. A) Evaluation of peptide specificity for $\alpha$-thrombin exosites using oligonucleotides HD1 that blocks thrombin exosite I.
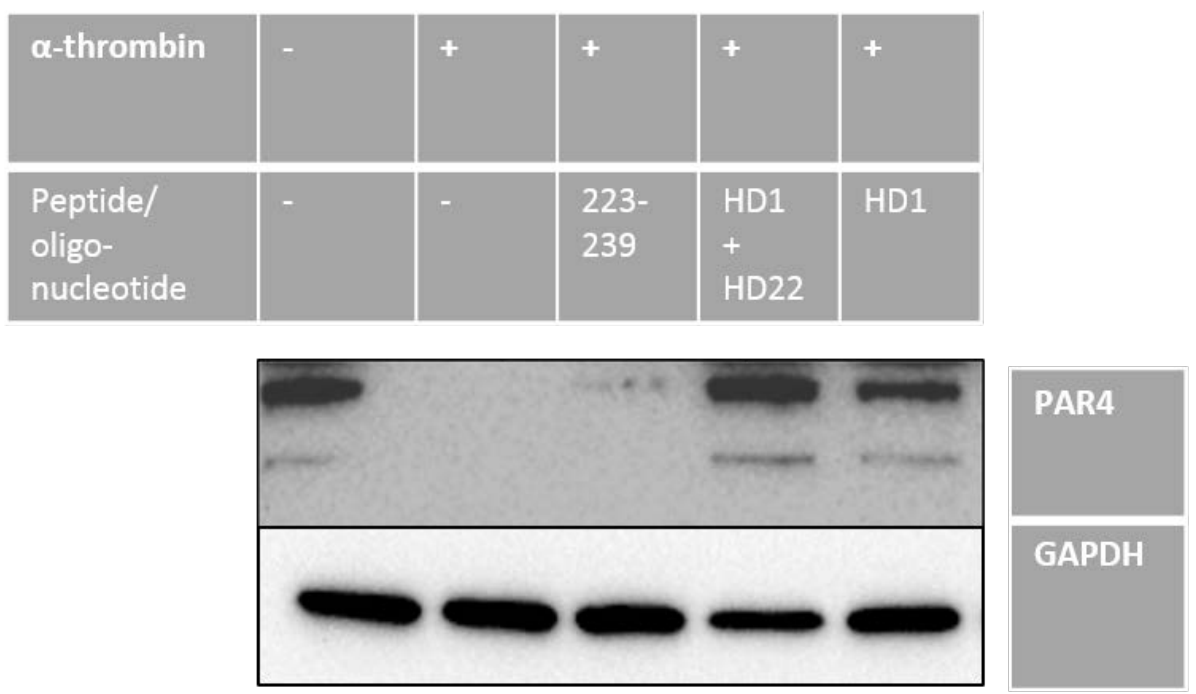

Figure 7 B) Evaluation of peptide specificity for $\gamma$-thrombin exosites using oligonucleotide HD1 to block thrombin exosite I and HD22 to block thrombin exosite II Effects on thrombin-induced cleavage of platelet PAR4 by peptides visualized by a monoclonal antibody directed towards the N-terminal of PAR4. Final concentration of $\alpha$-thrombin was $14 \mathrm{nM}, \gamma$-thrombin $20 \mathrm{nM}$, peptides $600 \mu \mathrm{M}$, and HD1 and HD22, both oligonucleotides at $2 \mu \mathrm{M}$. Conditions of incubation of platelets are depicted in the panel. GAPDH was used as loading control (lower band). 


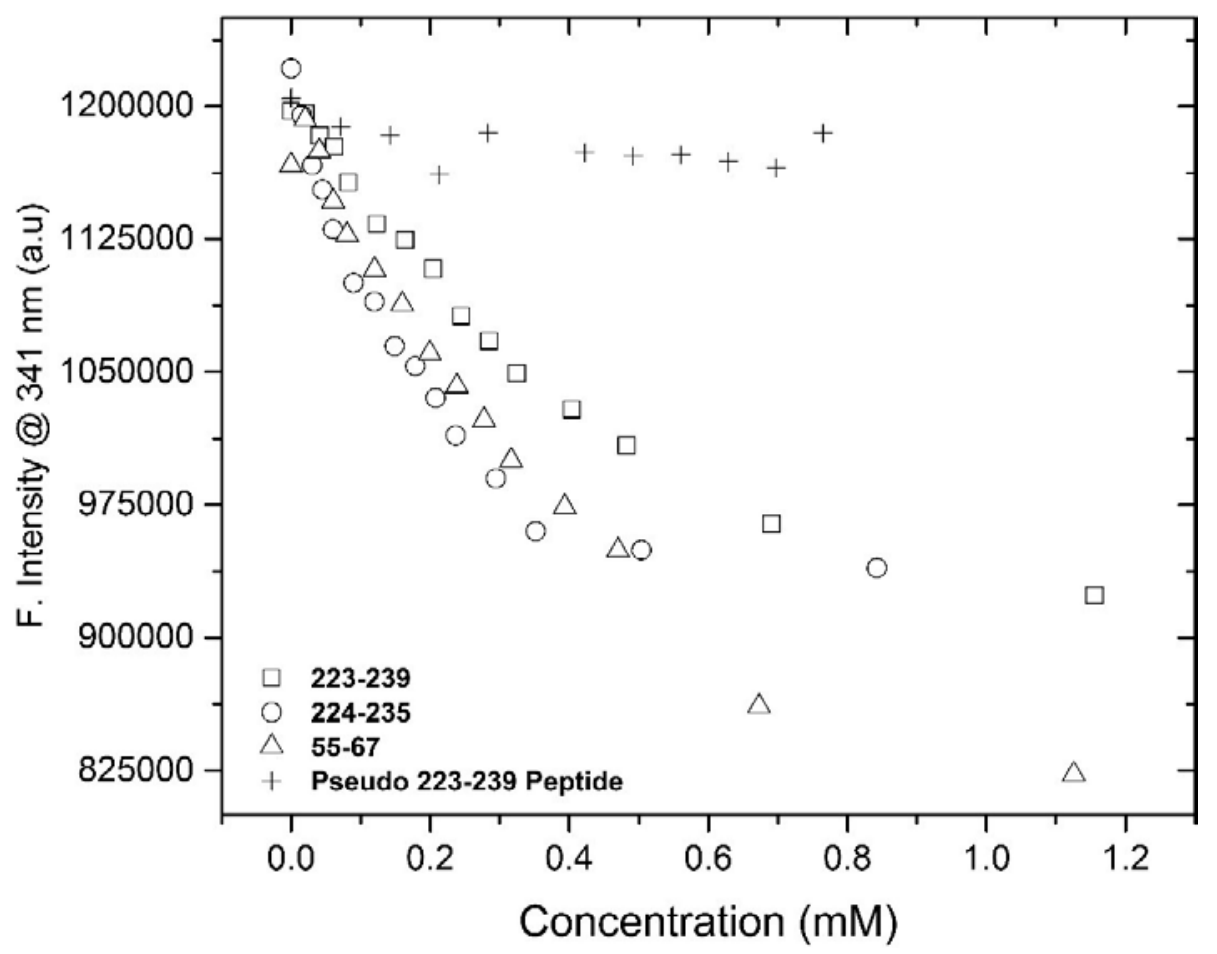

Figure S-8. Tryptophan fluorescence quenching of $\boldsymbol{\gamma}$-thrombin upon peptide

binding. Decrease in fluorescence intensity of $\gamma$-thrombin, measured at its $\lambda_{\max }$ (341 $\mathrm{nm}$ ), is plotted against increasing peptide concentrations. Addition of Pseudo 223-239 peptide did not lead to a significant decrease in fluorescence intensity of thrombin, which indicates that this peptide does not interact with $\gamma$-thrombin. 
SUPPLEMENTAL TABLES

Supplemental Table 1. List of plasmids

\begin{tabular}{|c|c|c|c|}
\hline \multicolumn{4}{|c|}{ Plasmids used in this work } \\
\hline Name & Features & Source & Aim \\
\hline p426GPD & $\begin{array}{l}\text { Terminator: CYC1, >, 20042264, } \\
\text { MCS: XhoI...XbaI, >, } 22652339 \\
\text { promoter for expression: GPD, <- } \\
\text {, } 23393019 \\
\text { marker(s): ampR, <, 41385068; } \\
\text { URA3, >, 2001300; } \\
\text { replicon: } 2 \text { micron, }\end{array}$ & $\begin{array}{l}\text { Dr. Simon Dowell, } \\
\text { GSK (UK) }\end{array}$ & $\begin{array}{l}\text { Expression } \\
\text { in yeast }\end{array}$ \\
\hline $\begin{array}{l}\text { P426GPD } \\
\text {-PAR4 }\end{array}$ & $\begin{array}{l}\text { p426GPD derivative by integration } \\
\text { of PAR4 cDNA on SpeI and SmaI } \\
\text { restriction sites. }\end{array}$ & Our lab & $\begin{array}{l}\text { PAR4 } \\
\text { expression } \\
\text { in yeast }\end{array}$ \\
\hline $\begin{array}{l}\text { pPGK- } \\
\text { AdA }\end{array}$ & $\begin{array}{l}\text { Insertion of Adenosine deaminase } \\
\text { on original pPGK plasmid }\end{array}$ & $\begin{array}{l}\text { Dr. Simon Dowell, } \\
\text { GSK (UK) }\end{array}$ & $\begin{array}{l}\text { Positive } \\
\text { control for } \\
\text { lacZ assay }\end{array}$ \\
\hline $\begin{array}{l}\text { pCDEF3 } \\
\text { PAR4 }\end{array}$ & $\begin{array}{l}\text { pCDEF3 derivative by integration } \\
\text { of PAR4 cDNA on EcoRI-XbaI } \\
\text { restriction sites }\end{array}$ & $\begin{array}{l}\text { Dr. Athan } \\
\text { Kulioupulos, } \\
\text { Tufts University } \\
\text { (Boston, USA) }\end{array}$ & \\
\hline
\end{tabular}


Supplemental Table 2. List of microorganisms

\begin{tabular}{|c|c|}
\hline \multicolumn{2}{|c|}{ Microorganism strains used in this work } \\
\hline S. cerevisiae Strains & Genotype \\
\hline MMY12 & $\begin{array}{l}\text { MATa his3 ade2 leu2 trp1 ura3 can1fus1::FUS1-HIS3 FUS1- } \\
\text { lacZ::LEU2 far1::ura3 gpa1_::ADE2 sst2::ura3 ste2::G418R } \\
\text { TRP1::GPA1 }\end{array}$ \\
\hline E. coli strains & Genotype \\
\hline BMH 71-18 mutS & $\begin{array}{l}\text { thi, supE, } \Delta \text { (lac-proAB), [mutS::Tn10][FminproAB, } \\
\text { lacIq Z } \Delta \mathrm{M} 15]\end{array}$ \\
\hline DH10B & $\begin{array}{l}\mathrm{F}-\text { mcrA } \Delta(\text { mrr-hsdRMS-mcrBC) } \Phi 80 \text { lacZ } \Delta \mathrm{M} 15 \\
\Delta l a c X 74 \text { recA1 endA1 araD139 } \Delta(\text { araleu }) \\
7697 \text { galU galK rpsL nupG } \lambda-\end{array}$ \\
\hline
\end{tabular}


Supplemental Table 3 Primers used for directed mutagenesis of PAR4

\begin{tabular}{|c|c|c|}
\hline $\begin{array}{l}\text { Primer } \\
\text { reference }\end{array}$ & $\begin{array}{l}\text { Mutation } \\
\text { generated }\end{array}$ & Sequence \\
\hline Q001502H1 & D235A & 5-GCGCTGCCCGCCGCACAGGCCTCC-3’ (fw) \\
\hline Q001502 & D235A & 5’-CGCGACGGCGACCGGCGTGTGCG-3’ (rv) \\
\hline Q0015F10 & D230A & 5’-GTGCTCTGCCATGCCGCGCTGCCCCTG-3’ (fw) \\
\hline Q0015F11 & D230A & 5’-CACGAGACGGTACGGCGCGACGGGGAC-3’ (rv) \\
\hline $768878 \mathrm{G} 1$ & D224A & $\begin{array}{l}\text { 5'-CTGGCGCGCTCCGAACGCGTGCTCTGCCAT- } \\
\text { 3'(fw) }\end{array}$ \\
\hline $768878 G 2$ & D224A & $\begin{array}{l}\text { 5'-ATGGCAGAGGCACGCGTTCGGAGCGCGCCAG- } \\
\text { 3’(rv) }\end{array}$ \\
\hline M8694H11 & D309A & 5'-CTGCATTACTCGGCCCCGAGC-3' (fw) \\
\hline M8694H12 & D309A & 5’-GACGTAATGAGCCGGGGCTCG-3’ (rv) \\
\hline M9411H11 & $\begin{array}{l}\text { D57A- } \\
\text { D59A }\end{array}$ & $\begin{array}{l}\text { 5’- } \\
\text { GTCGTGCCAATGCCAGTGCCACCCTGGAGCTC-3' } \\
\text { (fw) }\end{array}$ \\
\hline M9411H12 & $\begin{array}{l}\text { D57A- } \\
\text { D59A }\end{array}$ & $\begin{array}{l}\text { 5’- } \\
\text { CAGACACGGTTACGGTCACGGTGGGACCTCGAG- } \\
\text { 3' (rv) }\end{array}$ \\
\hline
\end{tabular}

